\title{
En el País de Nunca Jamás: la infancia en la poesía de Jorge Teillier
}

\section{From the Country of Nevermore: Childhood in Jorge Tellier's Poetry}

\author{
Claudio Guerrero Valenzuela \\ Universidad Católica de Valparaíso, Chile \\ claudio.guerrero@ucv.cl
}

- Resumen - Este estudio profundiza en uno de los temas poco estudiados de la poesía de Jorge Teillier: su representación de la infancia. Esta se presenta a través de la figura de un sujeto devenido en niño, una suerte de lazarillo del lar, quien muestra al lector un espacio poético habitado especialmente por niños, al cual se llega atravesando un espejo. Este espacio único resulta ser deslumbrante, luminoso y multicultural, reforzado por la presencia intertextual de la literatura infantil y juvenil. La infancia, finalmente, termina siendo reafirmada como un tiempo y un espacio de realización personal y estética.

Palabras clave: infancia, poesía, Teillier, estampa.

Abstract - The following paper reviews a topic that is not always considered when it comes to the poetry of Jorge Teillier: Childhood, presented in the figure of a boy, who becomes subject, a kind of blind person's guide that shows the reader a poetic living space inhabited especially by children; a place that can be reached through a mirror. This unique space turns out to be dazzling, bright and multicultural. It is reinforced by the intertextual presence of children's literature. Childhood, at the end, is reaffirmed as a time and space for personal and aesthetic realization.

Keywords: Children, Poetry, Teillier, Stamp. 


\section{LA RECEPCIÓN CRÍTICA}

Una parte de la crítica en torno a la poesía de Jorge Teillier -Jones (1981) y Candia (2007), entre otros- ha señalado que existe en su obra una recurrente alusión a una experiencia idealizada de la infancia que alude a un antes inmemorial, fundacional y originario, que alude a una Edad de Oro armoniosa en una Arcadia edénica, y en donde básicamente aparecen niños y jóvenes que pasan las horas maravillándose de la naturaleza ${ }^{1}$. Este verdadero invento de la memoria ${ }^{2}$, sin embargo, ha sido erróneamente delimitado por otro sector de la crítica en un tiempo y un espacio concretos, asimilándolas a la infancia real del poeta en su pueblo natal, Lautaro, en la primera mitad del siglo xx, y a la vida de sus antepasados que llegaron a vivir allí a fines del siglo xix. Stojkov (2001) y Traverso (2004), entre otros, han tratado de hacer notar este problema.

Otros trabajos críticos -Schopf (1996), Traverso (1999) y Binns (2001)- señalan que en esta poesía se intenta recuperar infructuosamente el dominio perdido de la infancia y su realismo secreto, signo de un tiempo mejor, fraternal e idílico. Producto de esto, su poesía sería el desgarramiento de un sujeto que intuye que su tarea es utópica y trágica: una poética del fracaso. De acuerdo a estas lecturas, el mundo lárico está condenado a la autodestrucción y termina por devorarse a sí mismo.

Esta idea es reforzada por Binns en su libro La tragedia de los lares (2001). En él señala que la búsqueda teillieriana de un orden y un tiempo de arraigo en el pueblo natal idealizado, en la naturaleza y en las cosas cotidianas es, ante todo, una actitud moderna: un anhelo de paz ante la anarquía, futilidad y liquidez de la vida cada vez más tecnologizada y rápida. Esta actitud -que él denomina método mítico (35)- sería una característica esencial de su poesía, que permitiría que vuelva permanentemente al tiempo de la infancia, símbolo del orden, la seguridad y la armonía vitales. Sin embargo, señala Binns, esta tarea romántica resulta «difícilmente sostenible: la intención mitificadora choca con la evidente temporalidad del espacio que el poeta procura intemporalizar (...), la edad de oro termina esfumándose, burlando los esfuerzos recuperadores del poeta lárico, y dejando evidente la imposibilidad de su búsqueda y la futilidad de sus anhelos» (39). Para Binns, esto se da porque el sujeto desarraigado intenta escapar del tiempo que le ha tocado vivir, haciendo de ese mundo mitificado de la provincia una gran ilusión que solo existe en la conciencia del sujeto, situación con la cual no concordamos. Veremos que es este, justamente, el valor que su poesía intenta inculcar: un sistema de creencias que busca instaurar otro orden, con otros valores a los convencionalmente aceptados por la sociedad, un orden comunitario marginal, situado en la periferia cultural, de carácter no pragmático, en donde hay

\footnotetext{
1 Estos estudios se han preocupado notablemente de establecer una relación entre esta poesía y ciertos tópicos provenientes de la literatura medieval pastoril: el paraíso perdido, la Arcadia, el locus amoenus, principalmente, y el desglose de sus características más específicas.

2 Dice el hablante de Crónica del forastero (1968): «Ninguna ciudad es más grande que mis sueños» (72).
} 
ausencia de poder y la naturaleza no está intervenida por la mano aniquiladora de los seres humanos, una poesía de la sencillez como contratexto a lo teórico, una utopía invertida convencida tanto más de la posibilidad subjetiva de su creación que de la fugacidad de su no lugar.

La crítica de Binns se sostiene en la idea de que a medida que se avanza en la lectura de la obra poética de Teillier, especialmente a partir de su cuarta producción, Poemas del País de Nunca Jamás (1963), el lector constata que este mundo no permanece estático, sino que se va degradando y erosionando por el avance del tiempo y las modernizaciones, haciendo que el sujeto se sienta cada vez más desarraigado, como un forastero que visita, cada verano, un pueblo fantasma, ajeno. En este sentido, es verdad, elocuentes son los títulos de dos de sus obras posteriores: Crónica del forastero (1968) y Para un pueblo fantasma (1978). Pero no nos confundamos: el problema que vemos en este tipo de explicaciones es que, por una parte, existe una lectura sesgada y generalizante que fija su punto de atención en unos pocos poemas que tematizan esta problemática y, por otra parte, que tiende a superponer la biografía del poeta a su poesía como si fuera algo inevitable, haciendo de la ruina de su vida personal (el alcoholismo, el exilio familiar, la pérdida real de la casa natal, el contexto dictatorial: el desarraigo) una manifestación de un fracaso poético, de su poética: esa pretensión no menor y destacada permanentemente por el autor en sus ensayos de unir arte y vida, la idea de vivir poéticamente ${ }^{3}$. Si bien Teillier manifestaba en un ensayo sentir una «nostalgia sí, pero del futuro, de lo que no nos ha pasado pero debiera pasarnos» (Muertes y maravillas 15) y que la nostalgia es «la única realidad» $(\mathrm{MM} 82)^{4}$, pensamos que los posibles arrestos de fracaso presentes en alguno de sus poemas -por ejemplo en «Señales» dice: «Antes de irse, el sol ilumina brutalmente / nuestro rostro condenado al fracaso» (PNJ 44); y, casi veinte años después, en otro poema dice: «He perdido el amor a la sombra y al misterio» (CRP 22) - no son más que expresiones de una lucha que finalmente el sujeto poético termina por ganar ${ }^{5}$, ya que hasta en sus dos últimos libros, El molino y la higuera (1993), el último publicado en vida, y En el mudo corazón del bosque (1997), el primero publicado póstumamente, la búsqueda de la imaginación se impone en el sujeto hablante más allá de toda biografía; pese a los años, al periodo dictatorial y a su creciente alcoholismo, pese a la enunciación de un futuro fracaso.

La recepción crítica de la obra teillieriana también ha presentado otro problema que quisiéramos destacar. Muchas lecturas de su obra, si bien resultan acertadas en

\footnotetext{
Dice Teillier: «El poeta es un ser marginal, pero de esa marginalidad y de este desplazamiento puede nacer su fuerza: la de transformar la poesía en experiencia vital, y acceder a otro mundo, más allá del mundo asqueante donde vive» (14).

4 Se ha decidido abreviar la referencia a los poemarios del autor para facilitar la lectura. La nomenclatura utilizada está detallada en la bibliografía.

5 Son frecuentes en esta poesía las alusiones a pugnas, luchas y oposiciones. Dos manifestaciones distintas son: las de tipo boxeril, que hacen de la figura del poeta y su condición en el mundo equivalente al trabajo de un púgil que debe pelear hasta el último round; y, las contraposiciones a otras poéticas como búsqueda de un espacio propio y diferenciado. Los golpes más evidentes van en contra de Lihn y de Parra.
} 
varios aspectos, se detienen excesivamente en las declaraciones ensayísticas del autor, partiendo de ellas, es decir, utilizando estos arrestos explicativos como argumentos y a los poemas como pruebas. De esta forma, la tarea crítica consistiría en determinar cuán fiel o cuán alejado a sus principios ha estado el poeta. Así, el lector especializado ajusta su horizonte de expectativas en relación a esas premisas para solazarse en el descubrimiento de que lo esperado se ha cumplido, o para poner en evidencia la «traición» del autor. Por ejemplo, si bien algunos autores destacan la gran capacidad de Teillier de crear atmósferas envolventes (Giordano, 1987; Valdivieso, 1997) como una cualidad expresiva excluyente, tal como el poeta lo defendiera, otros señalan que esta seducción termina generando la idea de un engaño en el lector, al dejar entrar ráfagas de tiempo y haciendo que el paisaje final sea uno de clínica y de bar y no la aldea y el bosque de siempre (Schopf 1996), desencadenando en el autor un proceso reversivo, de modo tal que "ya no cree en la existencia pasada del mundo lárico, ni en la posibilidad de representarlo poéticamente» (Traverso 1). Creo que una parte de la recepción crítica de la obra de Teillier se ha preocupado de poner en evidencia esa traición que, por cierto, intentamos desarticular.

Tres son los principales estudios sobre la presencia de la infancia en la poesía de Jorge Teillier. Para Jones (1981), la infancia es representada en la obra de Teillier como producto de una muerte verdadera que se da al crecer el niño, por eso su poesía vendría a ser el relato de una huerfanía: la expulsión del paraíso. Stojkov (2001) indica que la infancia es representada producto de un proyecto fenomenológico de dar cuenta de un modo de ser singular y único a partir de un desdoblamiento en el sujeto. Este doble le posibilita situarse en el plano de una sabiduría analítica -adulta- que retiene y considera la conciencia imaginativa del niño para redescubrir, finalmente, una inocencia perdida. De esta manera, el sujeto puede encontrarse, también, con sus antepasados: «El niño que aparece en la poesía de Teillier tiene el don de comunicar con seres de distintos siglos, con sombras y sueños de ancestros muertos» (148) . Por eso en Teillier, señala, la infancia es el tiempo más cercano a la muerte y hablar de ella implica, necesariamente, remitirse a un tiempo y un mundo muertos, que ya no están. Candia (2007), por último, afirma que en los poemas de Teillier el niño "es el único intérprete de los signos secretos de la realidad», por lo que el poeta «erige a la infancia, en definitiva, como una llave para acceder a un plano superior» (68). Ese plano superior sería la búsqueda de su poética, a lo cual Teillier logra acceder gracias al niño, haciendo de su poesía la «conquista del mundo soñado» (73). Por esto, el poeta puede recuperar la plenitud sensorial propia de los niños «para acceder a la tierra prometida» (74). Estos trabajos aportan una interesante mirada crítica sobre la infancia en la obra teillieriana, en especial a partir de la actualización de tópicos medievales como el del paraíso perdido, pero aun así pensamos que no han especificado lo suficiente cómo es realmente esta infancia que se manifiesta en su obra.

The children that appear in Teillier's poetry have the gift to comunicate with beings from different centuries, with shadows and dreams of dead ancestors (la traducción es nuestra). 
Todavía nos seguimos preguntando por qué el mundo de los poemas de Teillier es un mundo lleno de niños y niñas y qué papel juegan estos dentro de él. Creemos que la representación de la infancia es una aventura encarnada por un niño cautivo pero luminoso, una especie de lazarillo del lar que conduce a los visitantes. Una especie de Peter Pan, siempre niño, que atraviesa el espejo para mostrarle a ese visitante-que es tanto el sujeto desdoblado y autocaracterizado como forastero, como el lector que se siente atrapado y forzado (seducido) a adentrarse en él- un mundo maravilloso, análogo al de los relatos clásicos de la literatura infantil y juvenil.

Si bien gran parte de la poesía de este autor remite a un espacio y un tiempo situables históricamente - una aldea prototípica de La Frontera y sucesos acontecidos en ella más o menos entre fines del siglo xix y todo el siglo xx-, toda su poesía puede considerarse una gran invención que utiliza lo cotidiano pero cuyo espacio de realización es siempre otro: un lugar imaginado. Ese lugar es, en parte, una actualización lírica del tópico del País de Nunca Jamás, cuyo origen es la novela de James Matthew Barrie, Peter Pan y Wendy (1911). En esta se relata la historia de Wendy y sus hermanos, quienes son llevados por Peter Pan y su hada Campanita al país de los niños perdidos que no tienen madre y nunca crecen, donde todo siempre es diversión y aventura junto a temibles piratas como el Capitán Garfio, indios pieles rojas y animales peligrosos. El País de Nunca Jamás, dice el narrador de esta novela, equivale al mapa de la mente de un niño y su espacio lo describe así, entre todas las cosas que puede imaginar un niño, junto a sus recuerdos, sensaciones y experiencias:

El País de Nunca Jamás es siempre más o menos una isla, con sorprendentes manchas de color aquí y allá; y arrecifes de coral y naves que parecen volar a lo lejos; salvajes y guaridas solitarias; y gnomos que son casi todos sastres; y cuevas por las que pasa un río; y príncipes con seis hermanos mayores; y una cabaña a punto de desmoronarse; y una anciana muy pequeña con la nariz torcida (11).

Cada niño tiene su propio País de Nunca Jamás, distinto al de los demás, y puede ir allí mientras crea en él y siga siendo un niño «alegre, inocente e insensato» (228). Los adultos, en cambio, ya no pueden volver.

En los poemas de Teillier, los diferentes hablantes líricos de sus poemas -adultos que se hacen niños y niños en un presente eterno- aparecen asociados a un mundo como este, como en un encantamiento, donde todo brilla y solo existen aventuras y compañeros de juego, aunque a veces se viva con un tono adulto en un ahora citadino y precario. Creemos que teorizar sobre estas realidades dadas y no problematizadas al interior de sus poemas ha sido uno de los problemas de acceso a su poesía. Se trata de textos que, en cierto modo, se niegan a ser teorizados, que buscan ser, precisamente, lo contrario a toda posible teoría. Cómo trabajar con una poesía que aspira a la sencillez: es una limitación que queremos explicitar aquí. Por tanto, intentamos ofrecer una lectura de su obra que parte con esta traba. Creemos que en la obra de Teillier la vertiente biográfica, la modelización imaginaria que propone y el entorno vivencial de su época forman parte de una trama compleja que el poeta 
desarticula en su poesía, la procesa, para entregar al lector una poesía de la claridad, limpia y sencilla, que busca despojarse de las tensiones del mundo moderno, como si su tarea consistiera, precisamente, en liberar al lector de los problemas del mundo exterior y conducirlo a esta comunidad imaginaria, marginal, llena de niños y niñas.

\section{TEILLIER Y SU TEORÍA DE LA INFANCIA}

Antes de adentrarnos en el análisis, no podemos dejar de lado en este estudio un hecho inevitable: Jorge Teillier escribió en varias ocasiones algunas ideas en torno a la infancia. Las presentamos aquí no para usarlas a favor de nuestra interpretación, sino que como constatación de que la infancia es una parte central de su proyecto poético.

En uno de sus primeros ensayos emblemáticos, «Los poetas de los lares» (1965), Teillier expresa que la realidad tiene pocas enseñanzas, a no ser que se la mire «como un depósito de significados y símbolos ocultos» (50). Es tarea del poeta, entonces, dar cuenta de ese realismo secreto que permanece tapado y enfrentarse al caos del mundo para rehacerlo a través de «un nuevo mundo cerrado al cual invita a habitar: el poema» (50). De esta forma, el poeta debe buscar su lugar haciéndose un observador, cronista y transeúnte, «un simple hermano de los seres y las cosas» (51). Una de esas cosas ocultas es una Edad de Oro olvidada que el poeta tiene como objetivo reencontrar: «el paraíso perdido que alguna vez estuvo en la tierra» (53) y «cuya última muestra sería la infancia», como señala en su artículo «El gran Meaulnes cumple cincuenta años» (141). Como consecuencia de esto, el poeta podrá cumplir su tarea: "transformar la vida cotidiana del prójimo gracias a una poesía que muestre el rostro verdadero de la realidad» (54). Ese rostro verdadero vendría a ser la verdad, lo que el poeta considera como lo único, auténtico y esencial para la vida cotidiana: una poesía cercana, amistosa.

En otro de sus ensayos significativos, «Sobre el mundo donde verdaderamente habito» (1969), Teillier señala que la infancia forma parte del proyecto de su poesía porque «es un estado que debemos alcanzar, una recreación de los sentidos para recibir limpiamente la admiración ante las maravillas del mundo» (15). Este estado que debemos alcanzar se constituye como uno de sus métodos de construcción poética: la subjetividad infantil no contaminada aún por la vida adulta y que se maravilla por todo lo que le rodea. Pero también la infancia tiene otro cariz, como señala en «La terrible infancia» (1965), y es que existe, en esta secreta zona infantil, un lado oscuro, "pues la infancia no es solo el dominio de la pureza, sino que también allí los ángeles de las tinieblas extienden sus alas» (33). Con esto, el poeta se encarga de desacralizar la infancia entendiéndola, además, como un espacio que da cabida a la crueldad y a todo tipo de sombras. De esta manera, apreciamos que en Teillier la infancia cumple diversas funciones: es una idealización y una búsqueda, pero allí también se puede anidar el mal. 


\section{UN MUNDO DE ESTAMPAS}

La infancia es un componente habitual del mundo de la experiencia de los hablantes representados en toda la obra de Teillier, desde su primera hasta su última producción. Esto hace que sea un espacio poblado de niños y niñas ejecutando diversas acciones, especialmente juegos, en soledad o acompañados de adultos. Este mundo está lleno de creencias, fantasías, descubrimientos, ensoñaciones y maravillas asociadas especialmente a la literatura infantil y a ciertas tradiciones culturales. En ocasiones, eso sí, se vuelve oscura, con frecuentes alusiones a niños muertos. Se trata, en definitiva, de un mundo representado a través de estampas e imágenes que aparecen y dejan huella.

Resulta interesante destacar aquí las diferentes acepciones de la palabra estampa: 1. Reproducción de un dibujo, pintura, fotografía, etc., trasladada al papel o a otra materia, por medio de una prensa, desde la lámina de metal o madera en que está grabada, o desde la piedra litográfica en que está dibujada. 2. Figura total de una persona o animal. 3. Imprenta o impresión. 4. Huella (del pie del hombre o de los animales en la tierra). Y lo destacamos precisamente para afirmar lo siguiente: la plasticidad de la obra teillieriana, la viveza de sus imágenes, nos hace pensar en su poesía como un gran cuaderno de grabados cuya figura central son los niños y que puede ser leído (y mirado) tanto por infantes como adultos. Pero estos niños y niñas, además (apropiándonos de la polisemia del término), son infantes que dejan huellas como en los relatos infantiles, casi como escondiéndose, jugando, haciendo que el hablante vaya en su búsqueda. Son ellos los verdaderos protagonistas de una poesía construida para su rescate y exaltación.

Una de estas primeras huellas es la idea de una infancia situada en la nada, a la cual se le debe quitar su velo. En efecto, especialmente en la primera producción poética de Teillier, en los libros publicados entre 1958 y 1961, existe la constatación de que hay una experiencia previa a la existencia en el lenguaje: la infancia de la conciencia, aquello que permanece oculto hasta que se nombra o se hace conciente. Esto hace afirmar al hablante: «algo nos recuerda la verdad que amamos antes de conocer» (PAG 18). También en los siguientes versos:

El aire dice que una vez sonreímos por nada, y que nos conoce, desde antes que supiésemos quiénes somos, cuando éramos fantasmas entre ruinas contempladas por estrellas muertas hace siglos (PAG 36).

De acuerdo a esto, existe en esta poesía una experiencia, por decirlo así, inconsciente, que es previa a la realización en el lenguaje y que hace que las cosas le hablen al sujeto, para que este pueda descubrir su propia identidad. Es un sujeto que bien puede ser el equivalente al que está situado en el estadio del espejo lacaniano: la forma primordial del yo que antes de objetivarse en la dialéctica de la identificación con el otro, y antes que el lenguaje le restituya en lo universal su función de sujeto, necesita verse al espejo para identificarse y asumir una imagen de sí mismo. 
Esta actividad, de acuerdo al psicoanalista, es propia de los niños hasta la edad aproximada de dieciocho meses (Lacan 87). Así, estamos delante de un sujeto que no se reconoce aún en los espejos y se ve a sí mismo como un desconocido ${ }^{7}$. Por esto resulta comprensible que, si fijamos la atención en el análisis de las isotopías semánticas presentes en este fragmento $^{8}$, notemos la siguiente iteración: aire-nadafantasmas-ruinas-muertas, que nos remite a la idea de una infancia situada en el vacío, evanescente y fantasmal, un espacio ruinoso y muerto previo a la conciencia: «antes que supiésemos quiénes somos». Va a ser solo cuando las cosas terminen por ser reveladas, a través del sueño, que el sujeto descubrirá alegremente el mundo:

Tú eres un sueño que no recordamos:

pero que nos hace despertar alegres.

Una ventana abierta hacia el trigo maduro.

Busquemos grosellas junto al cerco

cuyos hombros abruman los cerezos silvestres (AM 43).

En este nuevo estadio, con un sujeto que ya establece una relación con la realidad a partir de su constitución por el lenguaje, los frutos tienen nombres particulares: grosellas, cerezos. De esta manera, como el niño que termina por aprender a conocer las cosas ya no solo tocándolas, chupándolas o rompiéndolas ${ }^{9}$, sino que nombrándolas, el sujeto realiza un movimiento similar para descubrir «el verdadero nombre de las cosas», o sea, aquellas cosas que han existido en la pura experiencia (la infancia muda, la infancia de ojos abiertos, sonora y táctil), pero que se vuelven reales «con solo nombrarlas»:

el espacio del silencio

entre mi voz y la voz de alguien

revelándome el verdadero nombre de las cosas

con solo nombrarlas: «álamos», «tejados» (TN 105).

De este modo, encontramos en los primeros poemas de Teillier una instancia reveladora: el sujeto abrocha la primera infancia, la del niño que se ve al espejo pero no puede hablar, aquella que es pura experiencia, pura mudez, aquella en donde todas las cosas aparecen a los ojos del sujeto y existen en la cotidianeidad, pero que, al no ser nombradas, no existían aún en la realidad lingüística del sujeto. Es entonces que el sujeto, ayudado por ese otro desconocido, esa «voz de alguien» que no reconoce pero que no es más que él mismo desdoblado, puede nombrar las cosas.

Esta figura del «desconocido» más tarde se trocará por la figura del «forastero», igualmente dislocado.

$8 \quad$ En el sentido trabajado por Rastier (1976).

9 En lo que vendría a ser en Piaget (1969), la fase sensomotora del niño y la niña. Esta concierne al periodo del desarrollo mental que es anterior al lenguaje, más o menos hasta los dieciocho primeros meses, y que se caracteriza por ser la etapa cognoscitiva y afectiva de niños y niñas, fuente de la construcción de lo real y de las posteriores operaciones del pensamiento. 
La siguiente huella la rastreamos cuando el hablante de estos poemas comienza a cruzar el espejo ${ }^{10}$. Como en Alicia en el país de las maravillas (1865) o como en Las crónicas de Narnia (1950), cruzar el espejo o atravesar el ropero es llegar a otro mundo. Ese otro mundo es el que se abre en su poesía. Allí aparecen los niños que nos ayudan a descubrirlo, allí surge una infancia permanentemente iluminada por un sol, una música y un cielo esplendorosos: un mundo donde todo deslumbra y resuena. Como señala Bachelard en La poética de la ensoñación, «la infancia ve el mundo ilustrado, el mundo con sus primeros colores, verdaderos. El gran antes que volvemos a vivir soñando con nuestros recuerdos de infancia es el mundo de la primera vez» (179). De ahí, entonces, que el sujeto de los poemas de Teillier sea un niño embobado ante el mundo exterior.

\section{EL ESPACIO DE LA MARAVILLA Y EL JUEGO}

El mundo poético de Teillier es un mundo poblado de niños y niñas que juegan. El juego, como señala Huizinga (1954), es un espacio de libertad que se da en una esfera temporal encerrada en sí misma, que cancela el mundo cotidiano y suspende la vida social (26-7). Efectivamente, los niños a los cuales el hablante alude están permanentemente ensimismados, suspendidos en su mundo propio y divirtiéndose con las cosas más insólitas: «buscábamos pancoras entre las piedras» (TN 101); burlándose de los borrachos: «El zapatero del barrio ya está ebrio, / y canta, entre risas de chiquillos» (PAG 54); o simplemente imaginando cosas: «los niños que corren entre castillos de madera» (TN 95). Son niños que transforman cualquier cosa en objeto de juego: «Tú también tienes poderes: / transformas una piedra en un soldado, / una rama en un caballo» (CF 68). En ocasiones, se disfrazan: «aparecen niños vestidos como guerreros de otra época / mientras giran los carruseles / entre la música de organillos resucitados» (PAG 37). Hay veces en que los niños juegan solos: cabalgan «en el balancín roto» (AM 76) o «juega en el tejado» con el reflejo del sol en un espejo (AM 47). O, como señala el hablante del poema «A un niño en un árbol», aludiendo al País de Nunca Jamás antes descrito: «Eres el único habitante / de una isla que solo tú conoces» (PNJ 37).

En este mundo plagado de niños, en definitiva, es habitual escuchar el canto de las rondas como sonido de fondo a la voz descriptiva del hablante: «En la plazuela / el forastero oye contar estrellas a los hijos del / carpintero. / Y luego una ronda: "Alicia va en el coche, carolín...» (PNJ 44). Estas rondas infantiles, además, de vasta tradición oral, son privativas de un mundo rural que conserva las tradiciones en comparación a la ciudad:

Se cantan rondas que ya no se escuchan en las ciudades:

Yo me quería casar

La idea de que la poesía de Teillier descubre el mundo previo al estadio del espejo y por eso puede atravesarlo pertenece a la profesora Magda Sepúlveda. Me permito aquí desarrollarla. 
con un mocito barbero.

Me sentaron en una silla

$y$ me cortaron el pelo... (CF 71).

Como expresa Huizinga, el juego crea un orden, un ritmo y una armonía que tienen que ver con la repetición, pero también con la musicalidad (23-4). Estos poemas rescatan esa dimensión del juego que, asimismo, le permite al niño «ser de otro modo que en la vida corriente» (46), una manera fantástica, por cierto, de vivir la cotidianeidad.

Pero esta poesía que reproduce diversos sonidos está llena, además, de imágenes de niños haciendo un montón de otras cosas. Se trata de ciertas estampas que permanentemente están aflorando y que completan un mundo arquetípico de niños y adolescentes. En ocasiones, algunas de estas imágenes tienen que ver con la experiencia temprana de la muerte: «Niños que se acercan al ataúd del amigo muerto» (PAG 21); «En las pupilas de un niño / de nuevo se dibujarán los pescadores / devorados por la viejas mareas» (CCH 30). Y a veces aparece personificada en el arquetipo maligno de la bruja que atemoriza con sus hechizos, similar al relato de la Bella Durmiente $(1697)^{11}$ :

\section{La muerte \\ esa manzana llevada por la bruja, ahora golpea los muros sin dejarnos dormir (CF 60).}

Las estampas -muchas veces metáforas finas, leves-, se configuran como pequeñas pinturas cuasi costumbristas de niños y niñas haciendo cosas, algunas aparentemente nimias o sin profundidad, pero que sin embargo van configurando este paisaje habitual, propio de una galería de exposiciones: «un niño descalzo / vuelve de la escuela / royendo un pedazo de pan» (PAG 60); «La hojarasca de las madres se arrastra llorosa / y los hijos solo hallan refugio en brazos de extraños» (AM 74); «Una niña que no sabe hablar / sigue hablando con su sombra» (PNJ 40); "A la entrada del pueblo unos niños vacilan / con el peso de brazadas de leña» (CF 86); «Pasan niños ciegos / Ellos siempre tendrán hambre de sol» (MM 76); «Llega una procesión de niñas vestidas de Primera Comunión» (MH 46). Se trata de niños y niñas que parecieran habitar un mundo propio en donde escasamente aparecen los padres. Se trata de infantes, además, que validan una cierta solidaridad entre pares: «Las primeras luciérnagas: / un niño corre a buscarlas / para su amigo enfermo» (MM 94); y sienten curiosidad por el mundo que les rodea: «Mi hija me pregunta: / ¿Dónde estuve yo antes / que

\footnotetext{
11 Este tradicional cuento europeo de origen oral cuenta la historia de una bella princesa de dieciséis años que ha sufrido un encanto por parte de una bruja maligna, pinchándola con una aguja para hacerla dormir eternamente. Un hada buena, para que todos en el castillo la acompañaran en su sueño, hace que todos duerman junto a ella. Pasan cien años y un día un caballero vence el hechizo al poder despertar con un beso a la bella durmiente.
} 
ustedes nacieran?» (MM 98). O la niña que de pronto aparece en un álbum, similar al cuadro de De Chirico «Misterio y melancolía de una calle» (1914):

Tarde de buganvillas. Hojeamos un álbum como el viento hojea las encinas del parque. Y aparece una niña que va hacia la glorieta vestida como estampa haciendo rodar un aro (PPF 30).

Hay otros niños, en cambio, que tienen actitudes más propias de la adolescencia: jóvenes «que coleccionan viejas revistas deportivas / y queman los libros de estudio al fin del año / escolar» (PPF 91); o que el domingo a la salida de la misa «se pasean con la moda recién llegada de / Santiago» (PPF 86). Hay otros, en tanto, que realizan pequeñas travesuras reprochables: "Vivo en un pueblo donde me llaman / el loco y los niños me tiran piedras cuando paso por / las calles» (CF 79) o en medio de acciones cargadas de cierta solemnidad, no sin algo de ironía por parte del hablante:

Le regalé al Cura Párroco

«La Mente Drogada. Cómo librarse de las Dependencias»

De los doctores Hudgson y Miller

Mientras un niño echa anilina a la pila del agua bendita (MCB 41).

Asimismo, en este paisaje habitual en donde los niños son actores disimulados de las descripciones del hablante, es plausible que aparezcan los adultos y, cuando lo hacen, asoman de modo contrapuesto. A veces, estos cobijan a los niños y les dan seguridad, por lo general, asociada a la figura arquetípica de la madre: «El que tuvo temor / escuchará junto a los suyos / los pasos de su madre» (CCH 38); «La madre apaga el fuego de la cocina y lleva a la / niña a su lecho» (PNJ 43). En otros momentos, aparecen acompañando la evolución física de los niños: «En los umbrales aparecen las marcas que señalaban / el crecimiento de los niños» (TN 102). Y en otras ocasiones dejan a los pequeños hacer cosas reservadas a los adultos, lo que a veces genera temor y en otras un agradecido aprendizaje, por lo general, asociado a figuras masculinas:

Te dejaron subir a la locomotora (...)

Te asomas alarmado a la ventanilla del vagón.

Tu padre bajó al andén para hablar con un amigo

temes oír de un momento a otro el silbato de partida (CF 69).

Los mayores aman salir de caza.

Te despiertan temprano.

Todo el día pasará de potrero a potrero, se treparán los cerros. (...)

A veces te dejan disparar

y aún te duele el hombro con el rechazo.

Te enseñaron que frotando pedernales se enciende una fogata (CF 88).

Sin embargo, hay un poema en especial en donde es posible esbozar una oposición de dos mundos que se vivencian de manera diferenciada. Se trata del poema 
«Juegos». En este se dice que: «Los niños juegan en sillas diminutas, / los grandes no tienen nada con qué jugar» (PNJ 23), como señalando una distancia insalvable entre dos formas de experenciar la vida: «Los grandes dicen a los niños / que se debe hablar en voz baja» (PNJ 23). Así, mientras los grandes se mantienen de pie «junto a la luz ruinosa de la tarde» (PNJ 23) y repiten que se debe hablar, disciplinadamente, en voz baja, los niños «reciben de la noche / los cuentos que llegan / como un tropel de terneros manchados» (PNJ 23), y se esconden bajo la escalera de caracol a contar todo tipo de historias. A los grandes, en cambio, les espera, y así termina el poema, el silencio: "vacío como un muro que ya no recorren sombras» (PNJ 23). En este contrapunto, entonces, encontramos la declaración de un anhelo: como el mundo de los adultos es sombrío, aletargado y ruinoso, es mejor conservar la frescura de la infancia, su luminosidad, sus juegos y cuentos. Y si bien se agradece que los adultos cuenten historias a los niños, se sabe, como señala Bachelard, que el niño no vive de las fábulas que les cuentan los adultos. Su más grande fábula, «que no le cuenta a nadie» (180), es la propia y nace de las soledades de su mundo interior.

Conciente de esta distancia insalvable entre el niño y el adulto, el hablante, en otra ocasión, se propone avisarles a los infantes y resguardarlos de aquello que les espera una vez que crezcan y se incorporen al mundo adulto, productivo:

Frente al semáforo rojo

me detengo

esperando cruzar la calle.

Un niño me mira

desde los brazos de su madre.

Algo tiene que decirme,

algo tengo que decirle,

algo que será él.

Hasta el cambio de luz

me hundo en esos ojos asombrados

irrecuperables (PPF 46).

En ese algo que el niño tiene que decirle también hay algo que él debe decirle a los niños: que la infancia es un solo gran tiempo, único e irrecuperable como el País de Nunca Jamás. Ese «algo que será él» no es más que lo esperado: un adulto apesadumbrado, un muerto en vida. Por eso, en esta poesía, los niños están llenos de vitalidad, mientras los adultos llevan vidas rutinarias, apagadas y sin sentido: algunos antiguos compañeros de curso son «oscuros oficinistas», otros «explotan la Revolución que no quieren», otros «sueñan con ser / gerentes» y algunos «duermen en vagones de carga y necesitan / tratamientos antialcohólicos y psiquiatras» (CF 79). Para rematar, el hablante señala en otro poema con algo de ironía hacia la modernidad trabajadora de las ciudades: «he visto día a día en las ciudades vehículos iluminados / como trasatlánticos / llevar rostros fatigados de un matadero a otro» (CF 96). Como en otros autores de la misma generación, por ejemplo en Barquero y en Lihn, esta oposición ilustra la visión crítica hacia una forma de vida cada vez 
más avanzada y moderna, que hace de los adultos fatigados y alienados hombres de trabajo, contraria, por supuesto, a una visión poética de la existencia.

Otra característica presente en esta poesía son las insistentes alusiones a niños muertos, acogiendo otro aspecto de la realidad del mundo que se describe. Dice el hablante en el poema «30 años después»: «El índice de tuberculosis y de mortalidad infantil era el más / alto del mundo» (MM 140). Efectivamente, era frecuente hasta hace poco en los pueblos, como en los conventillos citadinos, el temprano fallecimiento de niños y niñas, básicamente por las condiciones precarias de existencia de un país subdesarrollado ${ }^{12}$, lo cual está ligado a otro fenómeno extendido en todo el territorio, en especial en zonas rurales, propio de una tradición cultural de orígenes coloniales: el entierro de angelitos. Este ritual consistía en el entierro festivo de niños y niñas fallecidos con pocos años de edad que, se creía, eran reclamados por «el cielo». En él se comía, bebía, bailaba y cantaba. Al niño muerto, vestido entero de blanco, pintadas sus mejillas y boca con colores vivos, adornado con una corona de flores de papel plateado y provisto de unas pequeñas alas, se le solía atar a una silla y era subido a una especie de altar, en donde se le rezaba por una o dos noches antes de ser conducido al cementerio (Montecino 47) ${ }^{13}$. Es así como estos hechos innegables de la historia y cultura de nuestro país aparecen en varios poemas: «El aromo es el primer día de escuela (...) / es lo que nace de la semilla / de un hueso de niño muerto» (PAG 51); "al pie del roquerío / las algas envuelven con dulzura / el esqueleto del inocente» (AM 75); «Un ave de alas de hielo / deja a los niños el traje de la muerte / como disfraz para este día de frío» (AM 48); "En el techo de la casa vecina / se pudre una pelota de trapo / dejada por un niño muerto» (PNJ 47). En este plano es posible rastrear, además, un hecho de la biografía del poeta que se cruza en varios poemas, incluso en los últimos: la muerte de una hermana, a edad temprana:

Un chasquido se oye: es un chubasco

o un fantasma de un niño que vivió aquí hace tiempo

y vuelve a escuchar cómo la madre lee a su hijo (...)

la voz de la hermana cruza entre las nubes

la hermana que no conocimos (MCB 16).

La infancia que se recobra en esta poesía no llega a ser total sin la alusión frecuente, sobre todo hasta Crónica del forastero (1968), de un mundo de niños y adolescentes que tienen una serie de creencias, fantasías y descubrimientos, y que se maravillan con lo mágico que trasciende lo real, encontrando allí cosas secretas:

12 Como señalan Salazar y Pinto, (2002) hacia la tercera década del siglo xx (fecha que recrea el poema), la tasa de mortalidad infantil en Chile era la más alta del mundo. En 1873, al primer año de vida, correspondía al 33\%. Entre ese año y 1925 promedió 40\% (60).

13 En la película Largo viaje (1967) de Patricio Kaulen se recrea esta vieja tradición. El protagonista de esta película es un niño cuyo hermanito muere cuando la madre lo da a luz en el conventillo donde viven. Cuando el padre se lleva al nonato al cementerio (dentro de una caja de frutas) para enterrarlo por sus medios, el niño se da cuenta de que se le han quedado las alitas, por lo que va en busca de su hermano, para que pueda irse al cielo. 
Junto a la capilla del Bajo

las sonrisas de los fantasmas

se convierten en lilas (...).

Las fórmulas escapadas del libro de magia

se transforman en luciérnagas

que buscan profundas galerías.

El viento roba secretos al río y al cementerio

para contársela a la capilla abandonada,

y es necesario descubrir pronto esos secretos (PAG 54).

Se trata de un espacio que se nutre de una fuente cuádruple: las creencias e historias oídas a los antepasados mestizos, mapuches y franceses, por un lado, y las lecturas propias de la literatura infantil, por otro. Los ejemplos abundan y muchas veces estas vertientes se mezclan, sobre todo en el poemario Poemas del País de Nunca Jamás (1963). De este modo, así como las lilas son «las sonrisas de los fantasmas», los duendes nacen de la harina del molino: «Y entre la humedad y el moho, / abriendo puertas oxidadas, riendo ante las máquinas, / se pasean los duendes blancos / nacidos de la antigua harina» (PAG 56). Estos, además, son el temor de las niñas: «aquella que aún temía a los duendes / que salen de los rincones a robar nueces» (PNJ 33) ${ }^{14}$. Asimismo se celebra la noche de San Juan, cuando salen de sus cuevas todos los seres mágicos del bosque y trasladan al sujeto a un lugar desconocido, irreconocible, mientras hace presencia el diablo: «Aúllan los perros en casa del avaro / que quiere pactar con el Malo (...). / Ya no reconozco mi casa (...). / Despierto teniendo en mis manos hierbas y tierra / de un lugar donde nunca estuve» (AM 50). En la tradición española, durante gran parte de esa noche los niños suelen estar despiertos, juegan y cantan canciones tradicionales como "Aserrín, aserrán», se arman fogatas y hacen preguntas para averiguar sobre todas las cosas» (Plath 51). En Chile es una costumbre más bien rural y no tan extendida dentro de la población. La noche de San Juan, recordemos, es de tradición europea -especialmente española- y se relaciona con la celebración del Año Nuevo mapuche o We Tripantu -noche del 23 al 24 de junio-, porque ambas coinciden con la idea de un cambio de ciclo solar y con la idea de una noche de renovación.

En este espacio de recreación multicultural, en donde caben diversas culturas y tradiciones, las curanderas de la tribu -las machis ${ }^{15}$ - piden la sangre «de un inocente para calmar al océano" (AM 72), en lo que creemos puede ser una referencia al mito del diluvio en la religiosidad mapuche: para serenar al mar y a su dios, Caicai, la pareja de seres humanos sobrevivientes debía sacrificar a uno de sus hijos (Zapater 87). Respecto a esto último, resulta sorprendente constatar que efectivamente, a raíz del terremoto y maremoto de 1960, la machi Juana Namun-

14 En el imaginario mestizo-campesino chileno, los duendes son niños muertos sin haber recibido bautizo (Montecino 329).

15 La o el machi es, en la cultura mapuche, «una persona que por vocación -un ser 'escogido'- se destina al servicio de sanar. Es la mujer u hombre que intermedia entre el mundo de lo visible y el mundo de lo invisible» (Chihauilaf 77). 
cura, junto a otras dos personas, sacrificaron al niño José Luis Painecur, de cinco a siete años de edad, en Puerto Saavedra, para calmar las aguas, ya que creían que el terremoto se había producido producto del alejamiento de los mapuche de su religión (Rojas 526). Los elementos de la naturaleza, en tanto, cobran vida y se convierten en seres humanos, en otro rasgo propio de la sociedad mapuche: el animismo ${ }^{16}$. Así, el viento "ahora es ese niño desconocido / que se despierta para saludarnos / desde un cerezo resucitado" (TN 84), o las nubes son las que «me anunciaban que tú llegarías, / cuando despertaba para volverme / hacia la ventana de los sueños» (PNJ 30). Cuando un desconocido silba en el bosque «los patios se llenan de niebla", mientras "el padre lee un cuento de hadas / y el hermano muerto escucha tras la puerta» (PNJ 21). Esos sonidos -los chasquidos, los silbidos, las voces- solo son escuchados por estos niños maravillados por el mundo exterior, del mismo modo que el infante que es estimulado por notas musicales y canciones de cuna. El hablante que se hace niño para percibir y admirar estos sonidos sabe, sin embargo, que está solo: «nadie podrá comprender a los que oímos / a un desconocido silbar en el bosque» (PNJ 21), asumiendo lo marginal de su condición. El niño, como el poeta, es un ser marginal.

Otras descripciones profundizan estos aspectos multiculturales en las creencias de los niños, mezclando religiosidad católica (ángeles) con la mapuche (animización). Así, los niños tienen ángeles de la guarda que los cuidan «desde el corazón de los cerezos» (PNJ 29), es decir, ángeles de la naturaleza. Por otra parte, los niños pueden leer en el cielo el nombre «escrito por los pájaros» (PNJ 33) de la niña querida. Algunos creen, asimismo, que, una vez muertos, los niños son sembrados: "('Un niño se murió y lo sembraron', oí decir / a una niña de cuatro años)» (CF 60). Otros sienten temor de la noche, lo que les impide «ir a sacar agua al pozo» (CF 68). En tanto, si se avizora un tue-tué es porque trae consigo un mal augurio, por tanto «hay que ofrecerles pan y queso: / ellos volverán a pedirlo / transformados en hombres», y si una estrella cae es porque alguien morirá. Los niños, finalmente, deben decir: «Martes hoy, martes mañana, martes toda la / semana» (CF 68) para espantar a los muertos y brujos que se quieren hacer presentes en forma de pájaros. Esta serie de creencias vuelven a aparecer en el último libro publicado en vida por el autor, El molino y la higuera (1993), en el poema «Supersticiones», reviviendo la cosmogonía que se había perdido en sus libros del periodo dictatorial:

16 Respecto a esto, dos cosas queremos señalar acá. Primero, que concordamos con Lastra (2000) cuando señala que «un recurso constante en la obra de Teillier es el de las animizaciones y personificaciones» (7). Segundo, que una parte importante de este recurso proviene de esta cultura. Tomemos un ejemplo de un texto del poeta de origen mapuche Elicura Chihuailaf (1999): «Sentado en las rodillas de mi abuela oí las primeras historias de árboles y piedras que dialogan entre sí, con los animales y con la gente. Nada más, me decía, hay que aprender a interpretar sus signos y a percibir sus sonidos que suelen esconderse en el viento» (17). De acuerdo a esta tradición, el ser humano es considerado parte de la naturaleza, no ajena a ella. 
Si dos personas

se miran al mismo tiempo en un espejo

la amistad o el amor se romperán.

Tampoco regales nunca un dedal

aunque sea un dedal de oro.

No es bueno cambiar de sitio en una mesa

ni menos mecer una cuna vacía

porque morirán todos los niños que duermen en ella,

o tal vez nadie querrá tener un hijo en esa casa (MH 15).

Como podemos apreciar, el tema de las creencias está presente a lo largo de toda la poesía de Teillier y suele estar asociado a los niños, muy especialmente a niños muertos. Esta recurrencia forma parte del mundo oscuro de la infancia, donde no todo resulta maravilloso o alegre. Una infancia asociada a mitos de la tradición mapuche o producto de la propia experiencia epocal en un país signado por la mortalidad infantil y todo tipo de supersticiones.

\section{LA PRESENCIA DE LA LITERATURA INFANTIL Y JUVENIL COMO CONFIGURADOR DE LA EXPERIENCIA}

La representación maravillosa de la infancia en la poesía de Jorge Teillier no podría ser entendida sin sus constantes alusiones intertextuales a personajes e historias propias de la literatura infantil y juvenil. Estas alusiones casi siempre aparecen como una manera de reafirmar las sensaciones y estados de ánimos que se quieren exaltar, pero también en ocasiones se utilizan de modo distinto, en especial para hablar de una infancia precarizada dentro de un contexto político específico.

La experiencia del hablante suele estar signada por los libros leídos cuando se era niño: «La niebla del atardecer hace a todos personajes / de los libros de cuentos leídos en la torre que se / incendiará» (CF 67). Esto hace que su mundo evoque, siempre, la presencia de algún personaje libresco. Sin pretender ser exhaustivos basta con remitirse al «Poema XIX» de Crónica del forastero, como uno de los varios textos en donde se muestra el entusiasmo por las primeras lecturas, en donde las aventuras de sus personajes son «más reales que el mundo / donde vives» (CF 89): entonces allí aparecen la revista El peneca ${ }^{17}$, Emilio Salghari y su Sandokán (1900) ${ }^{18}$, Edmondo

Esta revista dirigida a un público infanto-juvenil circuló en Chile entre 1908 y 1960, editada por Zig-Zag y llegando a alcanzar, en su mejor época, un tiraje de 180 mil ejemplares en 1940 y siendo distribuida, además, en otros países latinoamericanos.

18 Llamado el «tigre de la Malasia», el héroe de esta novela es un príncipe de Borneo que ha jurado vengarse de los británicos, quienes lo desposeyeron de su trono y asesinaron a su familia, por lo cual se hace pirata. 
De Amicis y su Corazón (1886) ${ }^{19}$, Daniel Defoe y su Robinson Crusoe $(1719)^{20}$, Robert Louis Stevenson y La isla del tesoro (1883) ${ }^{21}$, Jonathan Swift y Los viajes de Gulliver (1726) 22, El pájaro azul (1908) de Maeterlinck ${ }^{23}$, las historias de vaqueros y las seriales que dan todos los domingos en la matiné del cine, entre muchas otras referencias literarias que se repiten de modo retrospectivo. Como señala Volpe (1993), todas estas referencias universales terminan por dar a la poesía un sello mágico, «un magnífico velo de lirismo» único e insuperable (113). Un campo signado por este código que remite a una experiencia de niñez y juventud.

Una de las figuras propias de la literatura infantil, nombrada de manera constante, es la Bella Durmiente del Bosque. Esta es resucitada de su sueño por la palabra poética: «Una lluviosa primavera resucita como de costumbre / hablando con las mismas hojas / que rodearon el sueño de la Bella Durmiente» (AM 75); «No volveremos al bosque, / cortaron los laureles. / La Bella Durmiente / los recogerá» (PNJ 35); «El invierno de la realidad oculta una Bella Durmiente / y ella despertará con las palabras / de los poetas de hace uno o dos mil años» (CF 81). La figura de la doncella del bosque permite al sujeto de estos poemas revivir la importancia del sueño como fuente primaria de la poesía y asignarle al poeta el rol de «despertador» de la conciencia. Por eso, cuando el hablante se pregunta: «¿En qué soñaba la Bella Durmiente / en su sueño que duró cien años?» inmediatamente se responde a sí mismo:

Amigo, no preguntes nunca

en qué soñaba la Bella Durmiente,

que este refrán te lo recuerde:

no hay mejor despertar que el sueño (PPF 29).

De la misma manera que esta joven cuando despierta ve todo como por primera vez y todo el bosque resuena a su alrededor, el poeta realiza el mismo movimiento descubridor al despertar del sueño. A través de este símil el hablante nos dice: no hay mejor despertar que ese, porque es el que permite ver todo como si se viera por primera vez. Es la imagen que hace posible la poesía, por lo que hay que recurrir todo el tiempo a ella. Esta actitud soñante es la que permite, entonces, mostrar lo que antes declaraba como verdadero: esa realidad secreta que hay que revivir en el poema.

Esta idea se expresa, quizás con mayor nitidez, en uno de los poemas más citados del autor. Me refiero a «Los dominios perdidos», el cual guarda un correlato

19 En esta novela se cuenta, en forma de diario, las vivencias de un niño italiano en un internado escolar a fines del siglo XIX y cómo experimenta situaciones que le hacen ir madurando.

20 En esta historia, basada en hechos reales, se cuenta las peripecias de un joven náufrago junto al sirviente Viernes en una perdida isla del Pacífico sur, frente a las costas chilenas (actualmente islas Juan Fernández).

21 Publicada originalmente por entregas en periódicos, esta novela es la historia del joven Jim, quien involuntariamente se ve envuelto en una aventura con temibles piratas en busca de un tesoro perdido.

22 Esta historia relata las aventuras del capitán Lemuel Gulliver, quien un día desembarca en un país habitado por seres diminutos, los liliputienses.

23 En esta obra teatral se escenifica la historia de un niño que quiere ayudar a su vecina enferma. Para tal efecto, un hada le ha pedido que encuentre el pájaro azul que la llevará a sanarse. 
con la novela de Alain Fournier, El gran Meaulnes (1913). Esta es la historia de un muchacho que se integra un día al pequeño curso de una escuela rural francesa y que con su particular manera de ser termina marcando para siempre la identidad de muchos de sus compañeros de curso, configurándose para ellos como un gran «compañero de juegos». El hablante de este poema le rinde un homenaje como si él mismo hubiese sido uno de esos compañeros: «En la noche apagaste las lámparas / para que halláramos los caminos perdidos» (TN 107), como si él mismo hubiese alumbrado lo que permanecía hasta entonces oculto, una verdad secreta:

Pues lo que importa no es la luz que encendemos día a día,

sino la que alguna vez apagamos

para guardar la memoria secreta de la luz.

Lo que importa no es la casa de todos los días

sino aquella oculta en un recodo de los sueños.

Lo que importa no es el carruaje

sino sus huellas descubiertas por azar en el barro.

Lo que importa no es la lluvia

sino sus recuerdos tras los ventanales del pleno verano (TN 107).

Aquello que es descubierto por azar -la huella: la estampa- es lo que se configura como algo relevante en esta poética: aquello que permite maravillarse ante el mundo circundante. Así, lo que queda es justamente esa actitud que debiéramos, pareciera decirnos el hablante, emular. Luego, cuando la sombra del gran Meaulnes desaparece, queda su verdad aprendida, brillante y sonora, que «solo hay compañeros de juego»:

La realidad secreta brillaba como un fruto maduro.

Empezaron a encender las luces de Lautaro.

Los niños entraron a sus casas. Oímos el silbido del titiritero que te llamaba.

Tú desapareciste diciéndonos: «No hay casa, ni

padres, ni amor; solo hay compañeros de juego» (TN 108).

Otro texto que alude al canon infanto-juvenil y en donde la infancia renace en el presente con la promesa de la alegría de volver a ser niño se da en el poema "A Coré» ${ }^{24}$ :

Hay una puerta labrada.

Miramos por la cerradura

$\mathrm{y}$ aparece un niño

semejante a todos nosotros,

mensajero del País de Irás y No Volverás

con el último «Peneca» en las manos.

(Lejos se oye el galope fantasmal de Herne el Cazador,

los cantos de los duendes en los bosques, las olas

rompiéndose contra la balsa de Robinson Crusoe...)

$\mathrm{Y}$ en el fondo de la casa sin muros del recuerdo

24 Coré fue el seudónimo de Mario Silva Ossa (1913-1950). Sus dibujos ilustraron las portadas e historias que aparecían cada semana en la revista El peneca. 
seremos otra vez los niños

que van a abrir el cofre

donde está el tesoro que creíamos perdido (PPF 102).

En este poema, el niño "semejante a nosotros» renace con la lectura de la revista El peneca, la que en su interior traía por entregas, y de manera ilustrada, historias como las de Herne el Cazador ${ }^{25}$ o Robinson Crusoe. Se trata de un hablante que al hacerse niño no puede dejar de agradecer el poder volver a experenciar lo vivido en esas lecturas de infancia. Por eso, el sujeto saluda al profesor de Matemáticas de Oxford, el reverendo Dogson -Lewis Carroll-, porque «nos deja en la primera casilla de otro mundo» (PPF 106) y porque gracias a él, «cuando lleguemos a la octava casilla / Empezaremos a ser reyes / En un juego que ya no vamos a olvidar» (PPF 106). El hablante, de esta manera, se sitúa en el plano del juego que marcó para siempre y que no se olvida nunca más. En ese juego que surgió al cruzar el espejo. Por eso su poesía va a estar llena de estos pequeños homenajes. Así se suceden una serie de otros textos dedicados a Robert Stevenson, Antonio Machado, Charles Dickens, Virginia Woolf, Edgar Allan Poe y otros. Por ejemplo, en el poema dedicado a Woolf: «Mañana espero ver de nuevo 'Islas de luz flotan / sobre el pasto' / como el niño esperaba la matinée del domingo» (HN 15). Es decir, «vestido» de niño.

Como dijimos, este entusiasmo por una infancia que renace en el presente, a través de la experiencia de la lectura de libros infantiles y juveniles, se mantiene en toda la poesía de Teillier, aunque hay un periodo que funciona como paréntesis dentro de su obra, el cual alude al contexto político dictatorial haciendo que la infancia se vea amenazada y ensombrecida, mostrando a niños que ya no juegan, por ejemplo, en las calles. En este caso, las referencias a la literatura también sirven para ilustrar las dificultades del momento: la infancia se vuelve otra, temerosa e insegura, la gente desaparece, se allanan las casas, falta la comida y hay que celebrar, irónicamente, que se ha sobrevivido un día más, como lo hace el sujeto de este poema asimilándose a la figura de Pulgarcito ${ }^{26}$ amenazado por un Padre asesino:

Ya desaparecieron las muchachas entre las dunas.

Hermanos, hay que encender el fuego

Con la leña traída

Por los hermanos de Pulgarcito.

(Ellos no saben que el padre

los va a llevar a morir al bosque).

25 Herne el Cazador es un personaje del folclore inglés. Cuenta la leyenda que, siendo uno de los jinetes reales del rey Ricardo II, quedó herido de muerto por la cornamenta de un ciervo al tratar de salvar al rey. Una bruja lo salvó a través de un encantamiento soldándole los cuernos a su cabeza a cambio de cederle sus habilidades en la caza. Al no ser reconocido por sus pares, Herne perdió el favor del rey y fue encontrado, una mañana, ahorcado en un roble. Desde entonces ronda como fantasma por los bosques y jardines de Windsor.

26 En la versión de Perrault, Pulgarcito es el menor de siete hermanos, hijos de unos pobres leñadores que no pueden alimentarlos por lo que un día el padre decide abandonarlos en el bosque. Allí se encuentran con un ogro y Pulgarcito logra escapar gracias a las botas de las siete leguas, volviendo a casa con su familia. 
Mañana no habrá nada que comer,

Hermanos, seamos felices:

Llegó la medianoche y aún estamos vivos.

Nadie ha venido todavía

A echar abajo nuestras puertas (PHU 7).

Son evidentes, en este poema y en otros similares, como lo han hecho notar Sánchez (1997) y Binns (1997), entre otros, este tipo de ironías que aluden al contexto político-histórico del momento de producción de la obra. Concordamos con Traverso cuando señala que la propuesta estética de Teillier no solo es ética, sino que social y política, lo que va muy en contra de cierta creencia de señalar esta poesía como una "poesía de la evasión». Resulta inexplicable, por decir lo menos, lo expresado por Vásquez en concordancia con Wright -traductora al inglés de una selección de poemas- de que en la obra de Teillier hay una "curiosa e interesante ausencia de tópicos políticos» ( Para hablar con los muertos»). Es más, en este espacio de inseguridad y temor social todo se ha vuelto fantasmal, y la música que antes resonaba en el sujeto ya no se escucha: "Y ni siquiera aquí se oyen las carretas / Cuya música he amado desde niño (PPF 77); "Entras a oír música donde tocan guitarras, / ya no existe el lenguaje que asombraba tu infancia» (CRP 26). Del mismo modo, el sujeto reclama irónicamente que bajo el mando de un gobierno autoritario se ha matado por decreto toda fantasía e imaginación y el Malo, el Cuco -arquetipo infantil para denominar eufemísticamente al Diablo ${ }^{27}$ - es un personaje real que tiene a todos atemorizados: «Han bombardeado todas las fábricas de los sueños y los niños / saben que existe el Cuco» (CRP 38). Con esto, vemos cómo se ha precarizado la infancia, haciendo de los niños, adultos:

Vivo en un tiempo donde mandan los padrastros.

Han asesinado al Grillo del Hogar.

Se recomienda el trabajo infantil,

y como a Oliver Twist

se condena a los inocentes antes de ser juzgados,

y las niñas no deben imaginarse

que las flores de los muros son tan vivas como las

de verdad (PPF 103-4).

En otras ocasiones, las imágenes son aún más terribles: «Ya no se juega sino en la Escuela de la Cimarra / que aplastará el Talón de Hierro. / Los niños del Futuro prefieren yacer bajo tierra / y hablan por ellos solo moribundos avellanos» (DP 163). Sin embargo, sabiamente, por decirlo de alguna manera, el hablante hace dormir a los niños para que estos no sean aplastados por el totalitarismo haciendo que hablen por ellos los avellanos y permitiendo que vuelvan a renacer más adelante, cuando soplen tiempos mejores.

27 La tradición cultural mestiza chilena designa al Cuco como «un ser perverso, que no posee forma definida, con que las madres o personas adultas amenazan a los niños desobedientes. Se cree que el Cuco se 'lleva' a los niños, pero que no los maltrata ni asesina» (Montecino 144). 
Sabemos que la literatura infantil clásica a la que alude Teillier en sus poemas ha sido tradicionalmente llamada -en alemán-el Märchen, en cuanto género instaurado por los hermanos Grimm y permanentemente actualizada en el cuento tradicional y en la llamada por Schiller, poesía ingenua. Se trata, en términos equivalentes, al cuento de hadas o cuento maravilloso. Sin embargo, más allá de sus características intrínsecas y de ser catalogada como una de las «formas simples», en palabras de Jolles (1958), de los sistemas y géneros literarios -lo que nos parece coincidente con esta poesía de la sencillez que postula el poeta-, el Märchen cumple una función que nos parece interesante. Como señala el propio Jolles, "cuando penetramos en el mundo del Märchen, destruimos el mundo de la realidad sentida como inmoral» (220), porque precisamente uno de sus propósitos es el de insertarse en lo maravilloso como crítica de lo real. Esta, creemos, es una de las tareas que se propone esta poesía: el escape de lo real, la utopía alienante que defiende, se construye no tanto como simple evasión, sino que especialmente como posibilidad de otra realidad, distinta, a la histórica. Una realidad poética en donde el niño y la niña salen de su condición marginal para constituirse en sujetos con nombre, espacio y mundo dentro del cual se sienten parte, casi como dueños. Por tanto, la recurrencia a la literatura infantil y juvenil se constituye en esta poética no como escape, sino que como reafirmación del mundo cerrado al cual se invita entrar para servir de contraste con ese otro mundo de «allá afuera»: la vida cotidiana, la realidad fatigada del mundo moderno. En ese plano, la ironía es uno de los mecanismos que mejor retrata esos contrastes.

\section{LA REAFIRMACIÓN DE LA INFANCIA}

En las últimas publicaciones de Teillier, El molino y la higuera (1993) y En el mudo corazón del bosque (1997), es posible apreciar que esta poética de la infancia no se ha agotado, contrariamente a lo señalado por la crítica ${ }^{28}$, y que, más aún, se reafirma por completo. Es decidor, por ejemplo, el epígrafe que abre El molino y la higuera, en donde se dice:

No pises este lugar.

Ayer tarde había, por aquí,

luciérnagas!

Issa.

Con esto, el hablante pareciera decirnos que existe un reino sagrado que todavía debemos cuidar y el cual no está permitido marchitar. El mensaje, además, suponemos que ha sido realizado por una niña, una especie de guardiana de esta casa de infancia. Ese reino de la ensoñación hace que el sujeto hablante de estos poemas conserve cierta pureza y entusiasmo por las cosas: «La boina blanca de la luna llena / se inclina sobre la muralla de magnolios / y me sonríe como una actriz

28 Como señalábamos al comienzo respecto a quienes proponen defender la idea de una «poética del fracaso". 
de Cine Mudo»(MH 17). Más aún, el hablante confirma a sus «compañeros de juegos», de los cuales ha recibido muchas cartas, que no les ha contestado porque deben comprender que siguen estando junto a él, que «para mí nunca han salido de Chile» (MH 22), es decir, que siguen viviendo en su imaginación del mismo modo que todos los héroes de las primeras lecturas. Con esto se encarga de desmentir toda posible oposición entre un antes mejor y un ahora ruinoso. Así, cuando alguien le pide que escriba sobre los membrillos «suspendidos frente a la ventana del cuarto de madera» (MH 28), si bien el sujeto señala que ya "pasó el tiempo de ir a la escuela golpeando membrillos / en los cercos» (MH 28), estos igualmente siguen importando tanto «como cualquiera de sus frutas amigas / no sin antes, escogido entre tantos, / no sin antes darle un beso en la mejilla / en nombre tuyo» (MH 28), como queriendo decir que todavía las cosas tiene algo que decirle, del mismo modo que todavía hay cosas que se pueden nombrar, recordando, además, esa luminosidad y ese canto característicos que hacen que las cosas se presenten vívidas: «Ahora vuelvo a encontrar la luz que permitían los días / verdaderos / que en su rosario vuelven y vuelven a cantar / las nubes que las visitan / para enseñarles sus nombres» (MH 36). Repetimos las palabras recurrentes: luz-verdaderos-cantar-nombres, la sensorialidad de la infancia que es capaz de nombrar el lugar que habita.

Con esto, el sujeto nos señala que más allá de toda ventana que se pueda abrir para dejar entrar el tiempo corrosivo y destructor, se puede mantener una poética. Así lo corrobora el final de este poemario, al incluir dos poemas de René Char ${ }^{29}$ que han sido traducidos y reescritos. Uno se llama, precisamente, «El molino», y el otro, «La higuera», y ambos poemas son celebratorios, lo que nos hace recordar aquella crítica de Teófilo Cid sobre el primer libro de Teillier, señalando que este se configuraba como «un poeta de la ovación» (La Nación 7 de abril de 1957). En efecto, si el molino se presenta con un ruido de «golondrinas siempre blancas» $(\mathrm{MH}$ 52), que saltan, brillan, centellean «y marca el paso» ( $\mathrm{MH}$ 52), sobre la higuera se posa un picaflor que «al pararse sobre el desastre / en lugar de hambre, murió de amor» (MH 52). Si el molino representa al tiempo cíclico y la higuera es el árbol que da hojas, pero no frutos, ambas connotaciones terminan siendo anuladas para celebrar en uno su musicalidad y centelleo de golondrinas y en otro una manera amorosa de morir. En efecto, en este poema, la higuera, aunque estéril, es poética: es «el arbusto de una fe nueva» (MH 52). Ambos son signos de un triunfo sobre la temporalidad del ser humano y de las cosas. Ambos permiten señalar que la poesía es una forma de resistencia a esa condición. Con esto volvemos a confirmar lo señalado: la poesía de Teillier es la representación de una marginalidad elegante, una suerte de autoexclusión entendida por otros -en términos mercantilistas- como fracaso.

De esta forma se llega a un punto, en el último libro, de confluencia entre el sujeto y las cosas. Ahora son estas las que lo reconocen a él y no viceversa. Entonces el sujeto, una vez más, se vuelve pequeño:

29 Poeta francés (1907-1988). Autor, entre otras obras, de Furor y misterio (1950). 
Cuando en la tarde no soy nadie

Entonces las cosas me reconocen

Soy de nuevo pequeño

Soy quien debiera ser

Y la niebla borra la cara de los relojes en los campanarios (MCB 17).

Al volver a ser infante -fijémonos en la palabra mudo del título del libro-, no solo el sujeto se empequeñece, sino que también puede recomponer el tiempo en contraposición a ese que descompone: es la imagen de la niebla que borra la cara de los relojes. Entonces, el hablante reafirma una convicción aparentemente apagada: ser de nuevo pequeño es el deber ser del poeta, es quien se debe ser, siempre, todo el tiempo. Y recordemos por qué: porque de niño le fue entregada esa verdad a través del sueño: "Voy a decir solamente / que fui comprendido / cuando me dormí sobre un caballo de madera / y él me llevó al trote a la calle. / Era en 1939 / la noche del terremoto de Chillán» (MCB 23). En esta fe en el sueño que revela la verdad, una «nueva fe», el hablante funda su pretensión de verdad y puede descansar en ella, porque ese sueño le valió la comprensión de los demás. En ese sueño, en donde los niños parecieran ser lazarillos mudos de un visitante permanente, forastero, fronterizo, se erige, en definitiva, la posibilidad de un hogar, un lugar donde habitar, un espacio aparentemente perdido: «No tienes un hogar / no tienes un domingo después de misa / donde repartir pan a bulliciosos amigos» (MCB 44), cuando en verdad siempre estuvo ahí, en cualquier parte o en un bosque, en el mismo bosque donde la Bella Durmiente -ente pasivo; no productivo- duerme el más plácido de los sueños, en ese bosque donde se aprende a ser niño de nuevo, donde esperan los compañeros de juego y que no se debe olvidar, porque constituye un estado que debemos alcanzar, ese bosque al cual hay que pedir permiso antes de entrar, según la creencia mapuche, el lugar donde se recrean los sentidos para recibir limpiamente las maravillas del mundo. Por eso el reproche final es, a la vez, una reparación de esta convicción poética:

¿Has olvidado que el bosque era tu hogar?

$¿$ Que el bosque grande, profundo y sereno

te espera como a un amigo?

Vuelve al bosque

allí aprenderás a ser de nuevo un niño.

¿Por qué te olvidaste que el bosque era tu amigo? (MCB 54).

En definitiva, la infancia en la poesía de Jorge Teillier se presenta como un espacio de realización del sujeto devenido en niño. Especie de lazarillo de un lar ruinoso, quien va recogiendo las huellas dejadas por diversas estampas, cuyos protagonistas son los niños y las niñas. Estos hacen conciente una cierta realidad a través del lenguaje y atraviesan el espejo. Una vez realizada esta acción se encuentran con un mundo maravilloso donde todo es luz: el espacio del juego y el deslumbramiento. Un mundo habitado por muchos niños en permanente movimiento y acción. Un mundo multicultural lleno de creencias y antiguas costumbres. Un mundo que se refuerza, 
además, por la presencia intertextual de la literatura infantil y juvenil, de donde surgen toda una serie de personajes, historietas y espacios que ayudan a reconfigurar y recrear de manera más compleja este mundo descrito. Construcción frágil y utopía alienante para algunos, esta poesía que aspira a la sencillez como contratexto a lo teórico reivindica a la infancia como un tiempo y un espacio marginal de realización personal y estética, como un sistema de creencias y valores alternativos, como un espacio en donde hay ausencia de poder, postulando un orden comunitario en el cual no hay pensamiento pragmático y con una naturaleza apenas intervenida por la cultura. Desde allí, la infancia se levanta para hacernos participar de su mundo en un viaje análogo al de los relatos infantiles, como el de Peter Pan al País de Nunca Jamás: lleno de aventuras, peligros y emociones, pidiéndole al lector hacerse pequeño del mismo modo que lo ha hecho el sujeto de los poemas.

\section{REFERENCIAS}

\section{Bibliografía primaria}

\section{a) Obra poética}

Teillier, Jorge. Para ángeles y gorriones (PAG). 1956. Santiago: Universitaria, 1995. Medio impreso.

---. El cielo cae con las hojas (CCH). 1958. Santiago: Tajamar Editores, 2004. Medio impreso.

---. El árbol de la memoria (AM). 1961. Santiago: Tajamar Editores, 2004. Medio impreso.

---. Los trenes de la noche y otros poemas (TN). 1961. Santiago: Tajamar Editores, 2004. Medio impreso.

---. Poemas del País de Nunca Jamás (PNJ). 1963. Santiago: Tajamar Editores, 2003. Medio impreso.

---. Muertes y maravillas (MM). Santiago: Universitaria, 1971. Medio impreso.

---. Crónica del forastero (CF). 1978. Santiago: Tajamar Editores, 2003. Medio impreso.

---. El pasajero del Hotel Usher (PHU). Santiago: Imprenta Libertad, 1975, edición privada de 100 ejemplares, 9 p. s/n. Medio impreso.

---. Para un pueblo fantasma (PPF). 1978. Santiago: Ediciones Universidad Católica de Valparaíso, 2004. Medio impreso.

---. Cartas para reinas de otras primaveras (CRP). Santiago: Ediciones Manieristas, 1985. Medio impreso.

---. Los dominios perdidos (DP). 1992. Santiago: Fondo de Cultura Económica 1996. Medio impreso.

---. El molino y la higuera (MH). Santiago-México: Ediciones del Azafrán, 1993. Medio impreso. 
---. In order to talk with the Dead. Traducción y prólogo de Carolyne Wright. Texas: University of Texas Press, 1993. Medio impreso.

---. Hotel Nube (HN). Concepción: Lar, 1996. Medio impreso.

---. En el mudo corazón del bosque (MCB). Santiago: Fondo de Cultura Económica, 1997. Medio impreso.

\section{b) Ensayos y artículos}

---. «El gran Meaulnes cumple cincuenta años». Prosas. Santiago: Sudamericana, 1965. 141-43. Medio impreso.

---. «Los poetas de los lares». Boletín de la Universidad de Chile 56 (1965). 48-62. Medio impreso.

---. «La terrible infancia». Prosas. Santiago: Sudamericana, 1965. 33-4. Medio impreso.

---. «Sobre el mundo donde verdaderamente habito». Muertes y maravillas. Santiago: Universitaria, 1971. 9-19. Medio impreso.

---. Prosas. Santiago: Sudamericana, 1999. Medio impreso.

\section{Bibliografía secundaria}

Bachelard, Gastón. La poética de la ensoñación. 1960. México: Fondo de Cultura Económica, 1982. Medio impreso.

Barrie, James. Peter Pan. 1911. Santiago: Alfaguara, 2006. Medio impreso.

Binns, Niall. La poesía de Jorge Teillier: la tragedia de los lares. Concepción: Lar, 2001. Medio impreso.

---. «Reescritura y política en la poesía de Jorge Teillier». Acta Literaria 22 (1997). 97110. Medio impreso.

Candia, Alexis. «El paraíso perdido de Jorge Teillier». Revista Chilena de Literatura 70 (2007). 57-77. Medio impreso.

Carrol, Lewis. Alicia en el país de las maravillas. 1865. Santiago: Pehuén, 1984. Medio impreso.

Cid, Teófilo. «Teillier, poeta de la ovación». La Nación 7 de abril de 1957. Medio impreso.

Chihauilaf, Elicura. Recado confidencial a los chilenos. Santiago: LOM Ediciones, 1999. Medio impreso.

De Amicis, Edmondo. 1886. Corazón. Santiago: Pehuén, 1984. Medio impreso.

Defoe, Daniel. Robinson Crusoe. 1719. Santiago: Andrés Bello, 1988. Medio impreso.

Fournier, Alain. El gran Meaulnes. 1913. Santiago: Andrés Bello, 1981. Medio impreso.

Freud, Sigmund. «La interpretación de los sueños». Santiago: Ercilla, 1988. Medio impreso.

Giordano, Jaime. «Jorge Teillier: en el umbral de la ilusión». Dioses. Antidioses. Ensayos críticos sobre poesía Hispanoamérica, Santiago: Lar, 1987. Estudios sobre Teillier. 
Fecha de ingreso: 24 de septiembre de 2009. <http://www.uchile.cl/cultura/teillier/ estudios/5.html>. Sitio web.

Huizinga, Johan. Homo ludens. 1954. Madrid: Alianza, 2000. Medio impreso.

Jolles, Andre. Las formas simples. 1958. Santiago: Universitaria, 1972. Medio impreso.

Jones, Jullie. «El paraíso perdido de la niñez en la poesía de Jorge Teillier». Revista Chilena de Literatura, (1981), 16-7. Estudios sobre Teillier. Fecha de ingreso: 24 de septiembre de 2009. <http://www.uchile.cl/cultura/teillier/estudios/7.html>. Sitio web.

Lacan, Jacques. Escritos. Vol. 1. Buenos Aires: Siglo xxi, 2005. Medio impreso.

Lastra, Pedro. «Sobre Jorge Teillier». El árbol de la memoria y otros poemas. Santiago: LOM Ediciones, 2000. 5-9. Medio impreso.

Lewis, Carl Stuart. Las crónicas de Narnia. Tomo I: El león, la bruja y el ropero. 1950. Santiago: Andrés Bello, 1987. Medio impreso.

Maeterlinck, Maurice. El pájaro azul. 1908. Buenos Aires: Losada, 1938. Medio impreso.

Montecino, Sonia. Mitos de Chile. Diccionario de seres, magias y encantos. Santiago: Sudamericana, 2003. Medio impreso.

Perrault, Charles. La bella durmiente del bosque. 1967. Santiago: Chile Salo, 1990. Medio impreso.

---. Pulgarcito. 1967. Santiago: Zig-Zag, 1995. Medio impreso.

Piaget, Jean. Psicología del niño. Madrid: Morata, 1969. Medio impreso.

Plath, Oreste. Los juegos en Chile. Aproximación histórica-folclórica. 2008. Santiago: Fondo de Cultura Económica, 2009. Medio impreso.

Rastier, Francois. «Sistemática de las isotopías». Ensayos de semiótica poética. Barcelona: Planeta, 1976. 107-40. Medio impreso.

Rojas Flores, Jorge. Historia de la infancia en el Chile republicano. 1810-2010. Santiago: Ocho Libros, 2010. Medio impreso.

Salazar, Gabriel y Julio Pinto. Historia contemporánea de Chile. Tomo V. Niñez y juventud. Santiago: LOM Ediciones, 2002. Medio impreso.

Salgari, Emilio. Sandokán. 1900. Santiago: Andrés Bello, 1997. Medio impreso.

Sánchez, Tomás. «La desintegración de un mundo y la ironía como respuesta». Acta Literaria 22 (1997). 79-96. Medio impreso.

Schopf, Federico. «El rojo esplendor de una catástrofe». La Época 12 de mayo de 1996. Estudios sobre Teillier. . Fecha de ingreso: 24 de septiembre de 2009. <http://www. uchile.cl/cultura/teillier/estudios/17.html>. Sitio web.

Stevenson, Robert Louis. La isla del tesoro. 1883. Madrid: Anaya, 1981. Medio impreso.

Stojkov, Teresa. "Jorge Teillier and a New Residence on Earth: the poetic imagination in contemporary Chilean poetry». Anales 3-4 (2001), 141-58. Göteborgs universitet. Fecha de ingreso: 1 de diciembre de 2009. <http://gupea.ub.gu.se/dspace/ bitstream/2077/3224/1/anales_3-4_stojkov.pdf>.Sitio web.

Swift, Jonathan. Las aventuras de Gulliver. 1726. Barcelona: Altaya, 1995. Medio impreso. Traverso, Ana. «Lo lárico y la recuperación de la historia». Estudios filológicos 39 (2004). 253-65. Medio impreso. 
---. «Las ruinas y Jorge Teillier». El Metropolitano 30 de mayo de 1999. Estudios sobre Teiller. Fecha de ingreso: 24 de septiembre de 2009. <http://www.uchile.cl/cultura/ teillier/estudios/12.html>. Sitio web.

Valdivieso, Jaime. «La otra realidad de Teillier». Trilce 1 (1997). Estudios sobre Teillier. Fecha de ingreso: 29 de septiembre de 2009. Fecha de ingreso: 24 de septiembre de 2009. <http://www.uchile.cl/cultura/teillier/estudios/3.html>. Sitio web.

Vásquez, Adolfo. «Para hablar con los muertos. Poética de la memoria; Trakl, Heidegger, Teillier». Diseño urbano y paisaje Vol. 3, 9 (2007). Fecha de ingreso: 1 de diciembre de 2009.<http://www.ucentral.cl/dup/9_para_hablar_con_los_muertos. htm>. Sitio web.

Volpe, Enrique. «Poeta renovador y respetuoso del pasado: Jorge Teillier». Atenea 468 (1993). 109-19. Medio impreso.

Zapater, Horacio. Aborígenes chilenos a través de cronistas y viajeros. Santiago: Andrés Bello, 1978. Medio impreso. 